\title{
Amereida en Valparaíso: un sueño utópico del siglo XX
}

\author{
Amereida em Valparaíso: um sonho utópico do século $\mathrm{XX}$ \\ Amereida in Valparaiso: an utopian dream of XXth Century
}

\section{Palabras clave:}

Arquitectura Latinoamericana

Arquitectura Chilena

Utopía Latinoamericana

Enseñanza de la Arquitectura

Amereida

\author{
Roberto Segre*
}

\section{Resumen:}

En 1952 se produce un cambio radical en la enseñanza de la arquitectura en la Pontifica Universidad Católica de Valparaíso, por iniciativa del arquitecto chileno Alberto Cruz Covarrubias y el escritor argentino Godofredo lommi. El nuevo punto de partida se basa en asumir la significación poética de la arquitectura como expresión del talento individual del creador; así como también de promover la inserción de alumnos y profesores en la realidad latinoamericana. El proyecto arquitectónico se inicia con un acto poético colectivo - llamada phalène -, que concreta la obra en un proceso dinámico y cambiante, sin definir formas y espacios a priori. Así surgieron en 1970 las viviendas y los edificios públicos de Ciudad Abierta Amereida, que materializa la utopía social y constructiva del equipo docente de la Universidad, cuyo proceso de transformación se mantiene hasta la actualidad. En un terreno situado a 30 kilómetros de Viña del Mar, en Ritoque, conformado por colinas y dunas frente al Océano Pacífico, se construyeron en forma aleatoria las ágoras que contienen las actividades sociales al aire libre, algunos edificios para la vida cultural - la sala de música -, un anfiteatro, un cementerio y las casas de los profesores, construidos por ellos mismos con la participación de los alumnos. Su configuración refleja la influencia del Surrealismo y de los movimientos artísticos contestatarios de los años sesenta. La cultura latinoamericana es asumida a través de la herencia cultural latina, una de las principales componentes de la historia regional: de allí, la relación con Virgilio y la Eneida que justificó la denominación de Amereida al conjunto de Ciudad Abierta. Esta experiencia utópica de la segunda mitad del siglo veinte, constituye una contribución importante, al representar un camino alternativo y cuestionador de los movimientos estéticos consagrados en la arquitectura de América Latina.

* Professor Titular, Programa de Pós-Graduação em Urbanismo (PROURB) Faculdade de Arquitetura e Urbanismo (FAU) Universidade Federal do Rio de Janeiro (UFRJ).

Doutor em Ciências das Artes, Havana Cuba, Universidade de Havana; Doutor Honoris Causa , Instituto Superior Politécnico “José Antonio Echeverria”, Havana, Cuba; Doutor em Planejamento Regional e Urbano, IPPUR, UFRJ. Pesquisador 1 A do CNPq; Pesquisador Emérito da FAPERJ. 
Resumo:

Em 1952 acontece uma mudança radical no ensino da arquitetura na Pontifícia Universidade Católica de Valparaíso, pela iniciativa do arquiteto chileno Alberto Cruz Covarrubias e o escritor argentino Godofredo lommi. O ponto de partida é baseado na proposta de assumir a significação poética da arquitetura como expressão do talento individual do criador; assim como também de promover a inserção de estudantes e professores na realidade Latino-Americana. O projeto arquitetônico é iniciado em um ato poético coletivo denominado phalène - que concretiza a obra em um processo dinâmico e mutante, sem definir a priori formas e espaços. Em 1970 foram criadas as moradias e edifícios públicos da Cidade Aberta Amereida que concretiza a utopia social e construtiva da equipe docente da Universidade, cujo processo de transformação se manteve até hoje. Em um terreno localizado a trinta quilômetros de Viña del Mar, em Ritoque, caracterizado por colinas e dunas na frene do Oceano Pacíico, foram construídas aleatoriamente as ágoras que contém as atividades sociais ao ar livre; alguns edifícios dedicados a vida cultural - o salão de música -, um anfiteatro, o cemitério e as casas dos professores, produzidas por eles mesmos com a colaboração dos alunos. As formas que as caracterizam refletem a influência do Surrealismo e dos movimentos artísticos contestatários dos anos sessenta. A cultura Latino-Americana é assumida através da herança cultural latina, uma das principais componentes da história regional: daí, o relacionamento com Virgilio e a Eneida como justificativa do nome Amereida outorgado ao conjunto da Cidade Aberta. Esta experiência utópica da segunda metade do século vinte, constitui uma importante contribuição, ao representar um caminho alternativo e questionador dos movimentos estéticos já consagrados na arquitetura da América Latina.

\section{Palavras chave:}

Arquitetura Latino-Americana

Arquitetura Chilena

Utopia Latino-Americana

Ensino da Arquitetura

Amereida

\section{Key words:}

Latin American Architecture

Chilean Architecture

Latin America utopia

Architectural Teaching

Amereida

\section{Abstract:}

In 1952 came a radical change in architecture teaching at Valparaíso Pontificia Universidad Católica: the Chilean architect Alberto Cruz Covarrubias and the Argentine writer Godofredo lommi introduced that revolution. The new starting point would encompass the poetic significance of architecture as an expression of the designer's singular talent, as well as involving students and teachers within Latin-American reality. The architectural design begins with a collective poetic act — called "phalène" - which identifies the work into a dynamic and changing process, without defining forms and spaces a priori. In 1970, it was begun the complex of dwellings and public buildings of "Ciudad Abierta Amereida", embodying the social utopia and constructive techniques of the teaching staff of the school, which is kept until today. In a site located thirty kilometers from Viña del Mar, in Ritoque, noticeable by its hills and dunes overlooking the Pacific Ocean, "agoras" for outdoor social activities were randomly constructed, some buildings for cultural life - a music room — an amphitheater, a cemetery and the teachers' houses, built by themselves with the help of the students. Its configuration reflects the influence of Surrealism and the art movements of the sixties. Latin-American culture is taken through its Latin cultural heritage, the main component of the regional history: hence, the relationship with Virgil and the epic poem Aeneid as a justification for the name Amereida given to the "Open City" complex. This utopian experiment of the second half of the twentieth century is an important contribution representing an alternative approach for questioning aesthetic movements already present in Latin-American architecture. 


\section{Amereida en Valparaíso: un sueño utópico del siglo $X^{1}$}

Según el pensador rumano Emil Cioran ${ }^{2}$ el mundo actual está más próximo del Apocalipsis que de la salvadora búsqueda de la utopía. En sólo una década desde el inicio del nuevo milenio, hemos asistido a continuos conflictos armados y tensiones religiosas que ocasionaron el magnicidio del WTC; a devastadores tsunamis, terremotos, sequías e inundaciones; a una profunda e interminable crisis económica mundial que generó millones de desempleados en el mundo desarrollado; un despilfarro estético y de recursos en la arquitectura corporativa de las grandes metrópolis, acompañados por la contrapartida del crecimiento exponencial de la población pobre, identificado en términos habitacionales con el Planet of Slums vaticinado por Mike Davis ${ }^{3}$. Ante este panorama sombrío y pesimista alcanzó una significativa vigencia la experiencia docente, arquitectónica y urbanística que desde hace más de medio siglo (1952) se desarrolla en la Escuela de Arquitectura y Diseño de la Pontificia Universidad Católica de Valparaíso. Basada en la integración íntima de alumnos y docentes en busca de los fundamentos poéticos de la creación artística, ella suscitó la necesidad de una vida en comunidad que se materializó con la creación de la Ciudad Abierta Amereida (1970), por iniciativa del arquitecto chileno Alberto Cruz Covarrubias (1917) y el poeta argentino Godofredo lommi (1917-2001) con un grupo de profesores de la Escuela.

Asumir la palabra y la poesía como germen inicial del proyecto arquitectónico, identificado en primer lugar con sus contenidos estéticos y culturales, surgido a su vez de la capacidad creadora de cada diseñador y enraizado en principios éticos y morales en el diálogo persistente entre alumnos y docentes, fue una constante en la metodología de diseño aplicada en la escuela a lo largo de cuatro décadas. El objetivo primordial, según palabras de Michael Löwy ${ }^{4}$, es motivar en los estudiantes "la pasión, la imaginación, la magia, el mito, el sueño, lo maravilloso, la revuelta, la utopía"; atributos que gestarían todo proyecto arquitectónico. En los años cincuenta, para lograr estos objetivos fue necesario llevar a cabo en la Pontificia Universidad Católica de Valparaíso un radical cuestionamiento de la enseñanza académica de la arquitectura, y eliminar la fría distancia entre alumnos y profesores, el estudio predominantemente libresco y teórico, y superar la ausencia de una experiencia práctica cotidiana que insertase a los estudiantes en la vida social urbana. Al mismo tiempo, en un mundo cada vez más dominado por el consumismo frívolo, el exhibicionismo formal, el predominio de la especulación inmobiliaria en las construcciones de las clases medias y altas; así como la pérdida del contenido humanista en las grandes metrópolis; lograr el difícil vínculo entre la actividad proyectual y un estilo de vida ascético y espartano, inspirado en los ideales éticos y estéticos que rigieron la arquitectura popular a lo largo de la historia.

En realidad, estas ideas no son nuevas. El cuestionamiento de los sistemas políticos, religiosos y filosóficos dominantes, ya en la antigua Grecia, motivaron la formación de pequeños grupos sociales alternativos, casi comunidades utópicas: recordemos el Jardín de Epicuro en Atenas; y el desarrollo del escepticismo y el estoicismo, tanto en Grecia como en Roma $^{5}$. La relación entre comunidad y arquitectura se remonta tanto a las cofradías de constructores medievales, a las corporaciones artesanales dedicadas a la construcción de las catedrales en las que 
existía una íntima relación entre arquitectos, escultores, constructores y aprendices, unidos por el fervor de llevar a cabo el mayor símbolo de la comunidad urbana; como a la búsqueda de la representación de la utopía urbana sobre la Tierra en los tratados religiosos, desde San Agustín hasta Campanella. En el siglo XIX, con la Revolución Industrial y el inicio del contexto arquitectónico kitsch creado por la burguesía, William Morris y John Ruskin se opusieron a la banalización estética del mundo material, alejada de la creación basada en el vínculo entre arquitectos, artistas y artesanos, identificados por el respeto a la naturaleza y la valorización del uso de los materiales tradicionales; y fomentaron la creación de pequeñas comunidades productivas de objetos de uso artesanales ${ }^{6}$. También volvió a surgir con los socialistas utópicos, la imagen de la ciudad ideal basada en relaciones sociales justas y equilibradas. Con el advenimiento de la "civilización maquinista", la escuela del Bauhaus (1919-1933) buscó un equilibrio entre el arte, la artesanía, la arquitectura, el diseño y la máquina; y al mismo tiempo lograr la integración de alumnos y profesores en la vida cotidiana, alternando el trabajo con el tiempo libre, desarrollados en el conjunto formado por el edificio docente, la residencia estudiantil y las viviendas de los maestros ${ }^{7}$.

Sin lugar a dudas en el siglo veinte, Frank Lloyd Wright (1867-1959) fue quien mas se aproximó a la idea de una comunidad utópica dedicada a la enseñanza de la arquitectura. En 1935, con una treintena de discípulos se asentó en el desierto de Arizona y con ellos construyó Taliesin West, formado por el edificio central de los talleres y los espacios de vida social; mientras los alumnos se instalaron en frágiles cabañas esparcidas en el territorio desértico ${ }^{8}$. En la ascética vida comunitaria, la creación arquitectónica estaba estrecha-

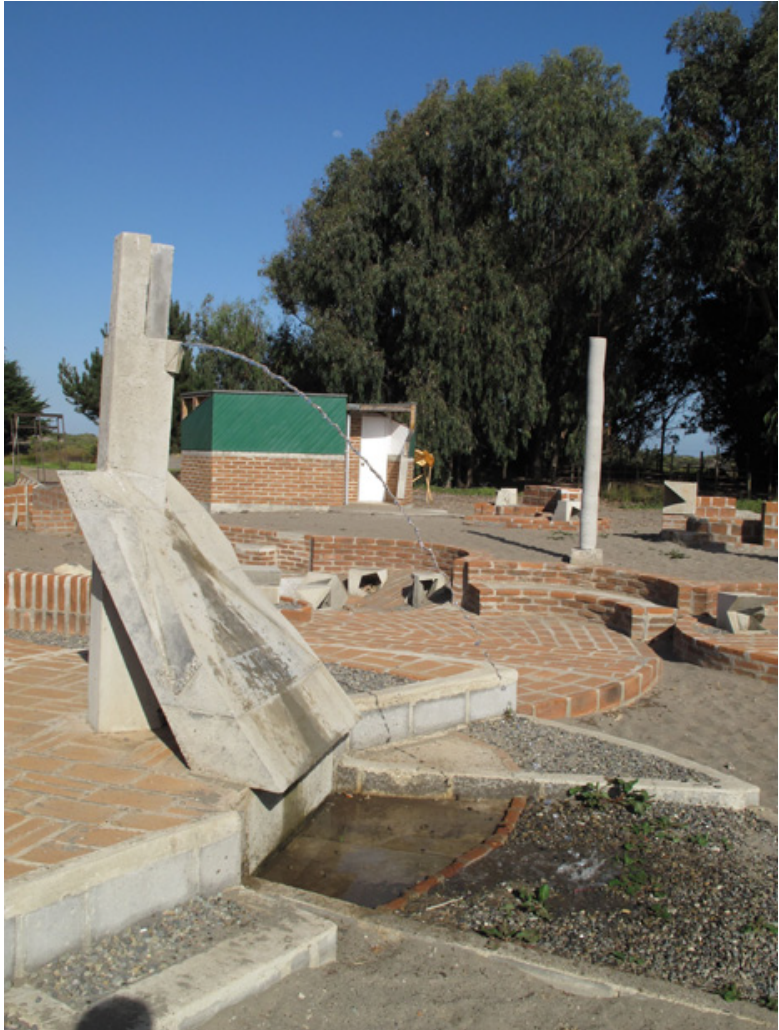

1 - Ágora. Espacio para el desarrollo de la vida social.

mente unida a las experiencias musicales, literarias y filosóficas que inspiraban la obra del Maestro. Entre los autores citados en su Autobiografía aparecen Ralph Waldo Emerson, Henry David Thoreau, Herman Melville, William James, Mark Twain, Walt Whitman, John Dewey y Charles Austin Beard $^{9}$. La íntima relación establecida entre teoría y práctica como fundamento de la enseñanza del diseño constituyó un principio que volvió a tomar fuerza a finales del siglo pasado e inicios del presente; en particular, en las regiones más pobres del planeta en las que no se concibe la arquitectura sin la participación de los usuarios, la comunidad, y el empleo de los recursos disponibles locales. Tuvo significa importancia el taller de Rural Studio creado por Samuel Mockbee en 1993 en colaboración con la Auburn University de Alabama, dedicado a construir proyectos de viviendas económicas para la población negra de Alabama y Mississipi ${ }^{10}$; y el reciente taller 
de arquitectura de Brian Mackay-Lyons y Richard Kroeker, de la Dalhousie University en Halifax, Nueva Escocia, en el que cada año los alumnos construyen colectivamente una casa con materiales vernáculos. Se trata de un camino alternativo a la arquitectura corporativa del jet set, elaborada en las gigantescas oficinas de las firmas internacionales, que despertó el interés de investigadores y críticos: el MoMA de Nueva York, organizó en 2010 una exposición sobre estas obras comunitarias "menores", denominada Small Scale Big Changes. New Architectures of Social Engagements ${ }^{11}$; y en Pamplona se celebró un congreso también dedicado al debate sobre la producción reciente del Tercer Mundo, bajo el título "Arquitectura: Más por Menos"12.

También en América Latina existe una larga tradición en la búsqueda de la integración entre arquitectura y comunidad, entre cultura, arte y trabajo manual, que se inició en el siglo XVII en las misiones jesuíticas de Bolivia, Paraguay, Argentina y Brasil, con el fin de crear agrupaciones indígenas ideales, que los prote- giese de la inhumana esclavitud a que eran sometidos por los colonizadores españoles y portugueses ${ }^{13}$. Más de treinta pueblos construidos, establecieron en el corazón de América un sistema urbano que aspiraba a representar el modelo de la "Ciudad de Dios" de San Agustín. En el siglo veinte acontecieron numerosas experiencias docentes en las que los alumnos colaboraron con los asentamientos espontáneos de los inmigrantes urbanos pobres: recordemos las experiencias de Carlos González Lobo en las comunidades indígenas mexicanas ${ }^{14}$; la participación de estudiantes en las tomas de tierras en Chile durante la Unidad Popular; y también en los "Pueblos Jóvenes" situados en los áridos suburbios de Lima $^{15}$. Una de las experiencias más importantes de la segunda mitad del siglo pasado es la iniciativa del prestigioso arquitecto Claudio Caveri (1928) en Buenos Aires, quién se instaló en una comunidad pobre en la Municipalidad de Moreno y creó la Cooperativa Tierra (1958); y con sus pobladores funda la Escuela Técnica Integral Trujui (1974),

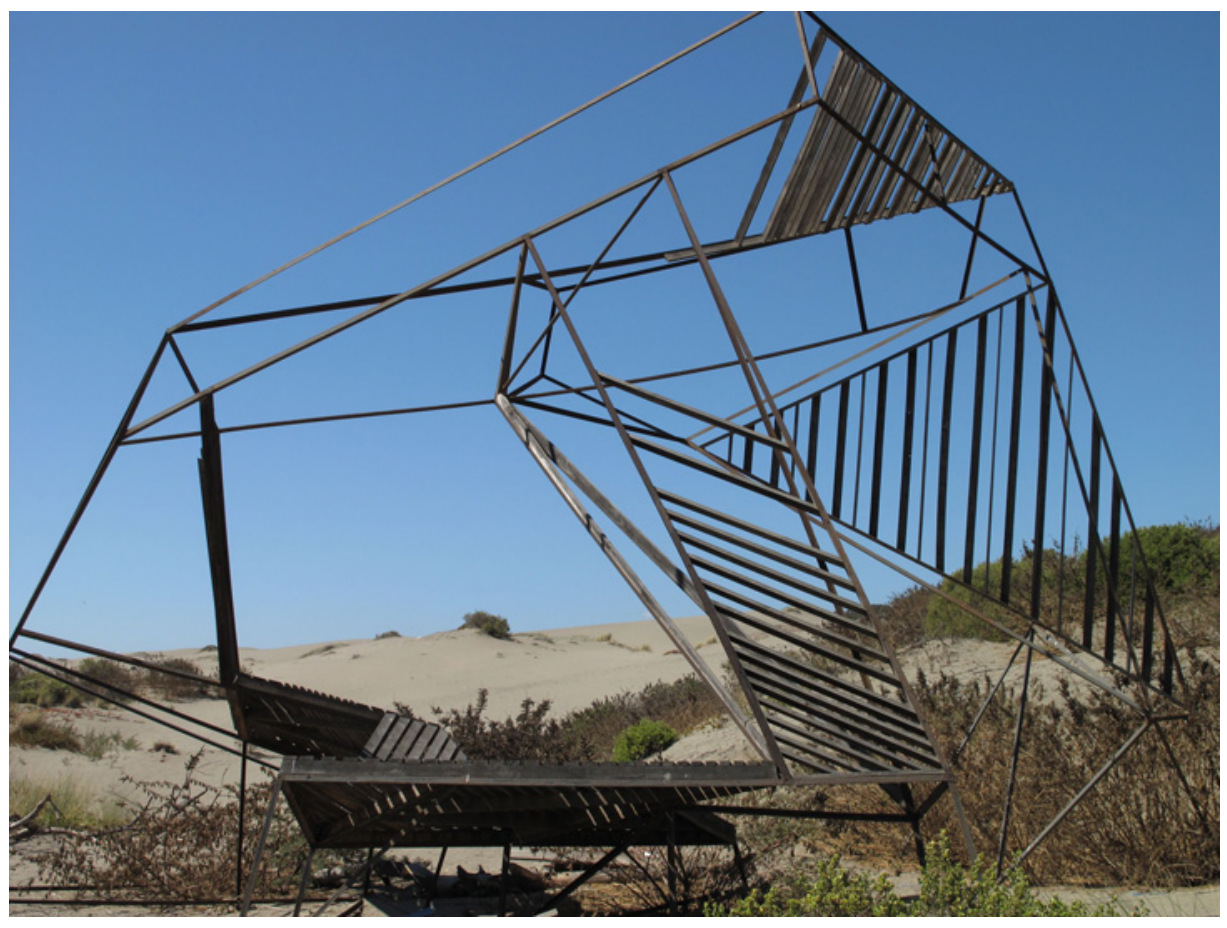

2 - Escultura realizada en uno de los actos poéticos, Phalène 
para formar a los futuros constructores de la región. Pero no se limitaba a una acción puramente técnica, sino que poseía un fundamento filosófico, histórico y social basado en el pensamiento católico de Teilhard de Chardin y Emmanuel Mounier, el existencialismo de Jean Paul Sartre, la filosofía de Martin Buber, y en los escritores y políticos argentinos: Rodolfo Kusch, Raúl Scalabrini Ortiz, Arturo Martín Jauretche, Ezequiel Martínez Estrada ${ }^{16}$. Y no podemos olvidar la significativa experiencia de Christopher Alexander, quien con un equipo de alumnos diseñó la propuesta arquitectónica y urbanística presentada al concurso internacional PREVI, organizado por las Naciones Unidas en 1969, que resolvía el hábitat popular en el Perú con los materiales artesanales locales, respetando a la vez las formas de vida y los hábitos de las comunidades pobres ${ }^{17}$.

En este contexto Cruz y lommi se plantearon crear en los alumnos, a lo largo del proceso creativo del proyecto arquitectónico, una clara conciencia de la particularidad del sitio urbano caracteriza- do por el duro contraste entre la Valparaíso histórica - integrada en 2003 en la lista del Patrimonio Cultural de la Humanidad de la UNESCO -, con su arquitectura espontánea de casas de madera y chapa corrugada, asentadas en el anfiteatro de los cerros; y Viña del Mar - donde está localizada la escuela -, prestigioso centro turístico del Pacífico - totalmente deformado por la especulación inmobiliaria -; y asimilar los atributos de la naturaleza local - la articulación entre los cerros y la bahía de Valparaíso -, identificada por la inconmensurabilidad del Océano Pacífico, la presencia de las colinas verdes y las movedizas dunas a lo largo de la costa. Pero al mismo tiempo crearles la conciencia de ser americanos. ¿Pero a que América desean pertenecer?. No a la representación del dominio colonial y de su sistema urbano de cartesiana geometría regular esparcido a lo largo de las costas del Atlántico y del Pacífico; ni a una modernidad dependiente de negativas y mimetizantes influencias externas. El objetivo es revalorizar la identidad original americana, bajo la égida de la cultura

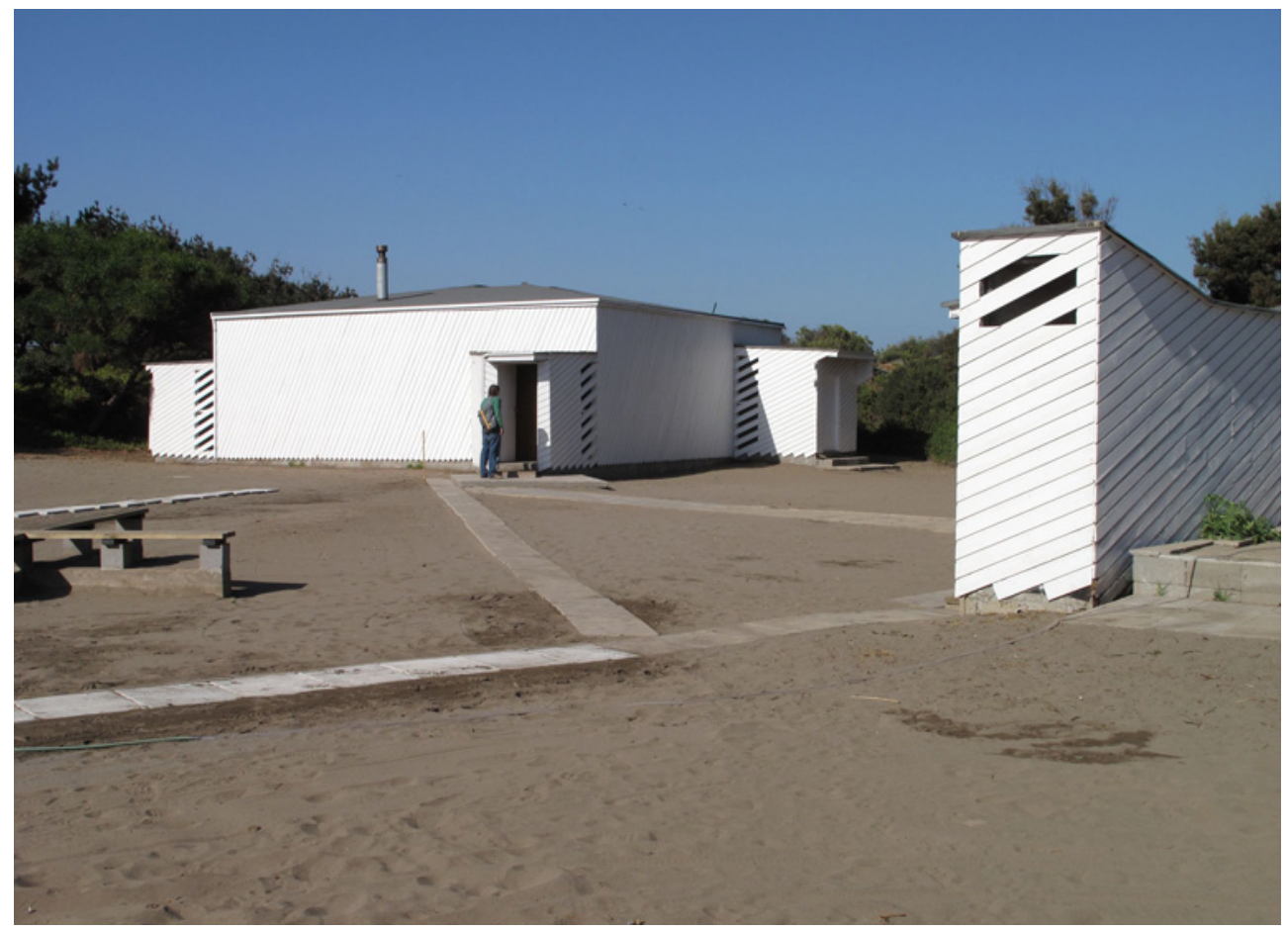

3 - Vista exterior de la Sala de Música 


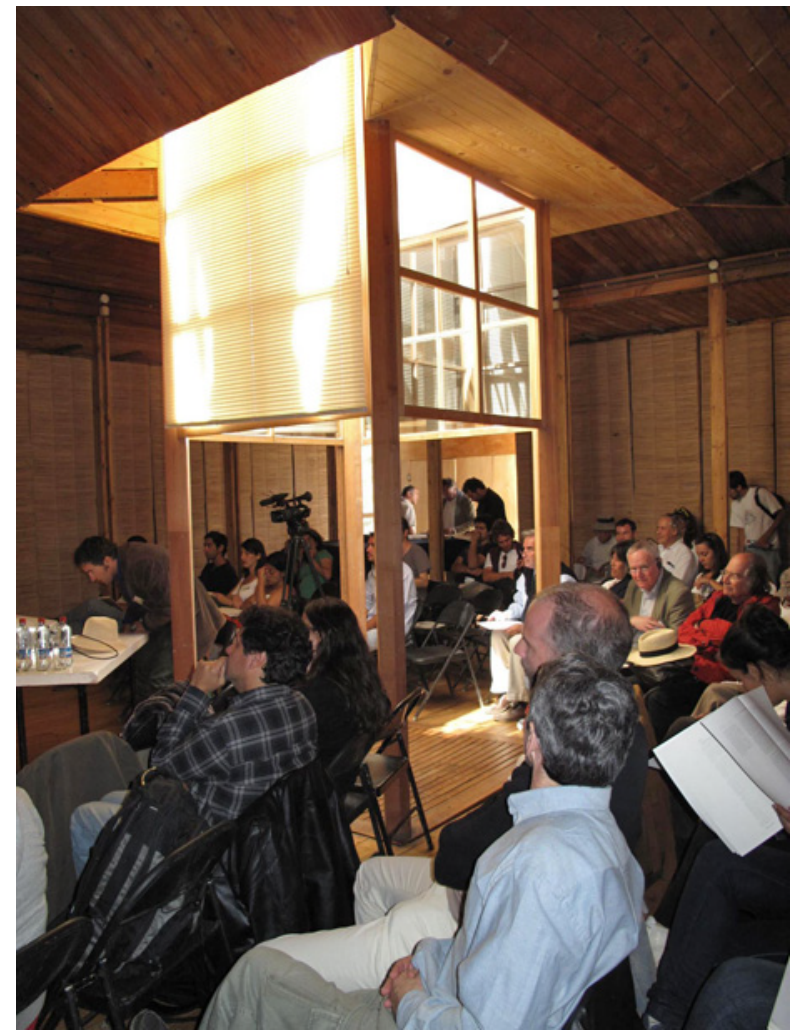

4 - El lucernario en el interior de la Sala de Música

occidental - según la tesis del mexicano Edmundo $\mathrm{O}^{\prime}$ Gorman $^{18}$ - en la epopeya de la construcción de una cultura y un sistema de vida basados en la articulación colectiva y en la libertad individual - "no se trata de cambiar la vida, sino cambiar de vida" -, cuya dinámica creativa, en constante evolución, se desarrolle en un diálogo con la auténtica naturaleza del Continente. Asimilar esa naturaleza "gnóstica", según el escritor cubano Lezama Lima, que constituye la esencia natural del ser americano, procesada en una síntesis con la cultura, al afirmar: "Árboles historiados, respetables hojas que en el paisaje americano cobran valor de escritura donde se consigna una sentencia sobre nuestro destino"19. Principios identificados con tres componentes básicos que definieron los objetivos docentes de la Escuela: la adopción de la palabra y la poesía como fundamentos de la arquitectura - según Cruz "el arte de la arquitectura para serlo, ha de oír a la palabra poética" -; la creación de Ciudad Abierta y los viajes exploratorios en el interior del continente.

El tema de la búsqueda de la poiesis de la arquitectura se remonta a las concepciones estéticas de Platón y Aristóteles, a la herencia literaria de Homero - la llíada y la Odisea -, posteriormente reelaboradas por Virgilio en la epopeya de la Eneida -; y de allí se asumió el ejemplo de la fundación de Roma, de su expansión territorial y cultural, integradora de diferentes pueblos e idiomas. Al sintetizar el encuentro entre América Latina y Europa en la palabra Amereida ${ }^{20}$; filtrada por las visiones dinámicas de la modernidad, e identificada desde 1965 en poemas y libros, se rescató la universalidad romana, ya que parafraseando a lommi, "América emerge medio a medio de lo desconocido. De su aventura, con ella, no solo hay un nuevo mundo sino por primera vez en la historia todo-mundo." A su vez surgió el vínculo estrecho con los literatos y artistas

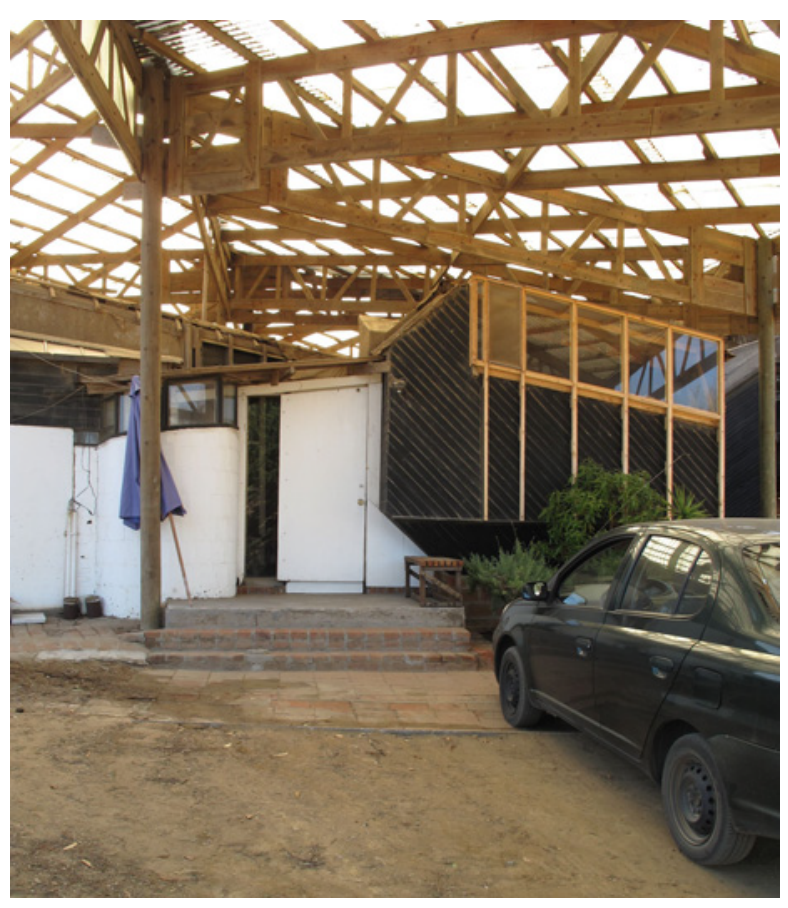

5 - La cubierta protectora de la Hospedería del Banquete 
simbolistas, dadaísta surrealistas y situacionistas, inspiradores de las acciones poéticas colectivas que anteceden al proyecto arquitectónico, denominadas Phalène; actos creativos que irrumpen en el espacio para transformarlo a través del juego lúdico de la poesía en acción. Resultó significativa la influencia de William Blake, Novalis, Stéphane Mallarmé, Arthur Rimbaud, Guillaume Apollinaire, Charles Baudelaire, André Breton, Guy Debord y el poeta local Pablo Neruda ${ }^{21}$.

Desde el inicio de la Escuela en 1952 se iniciaron los viajes por el Continente - las Travesías - con el objetivo de explorar el "mar interior" de América, o sea, en sentido contrario a los viajes de los colonizadores a lo largo de la costa 22 . Se propusieron recorrer el territorio desde Punta Arenas y Cabo de Hornos en el extremo sur de Chile, hasta Santa Cruz de la Sierra, en el corazón de Bolivia, declarada por ellos en 1965, "Capital Poética de América". Y desde entonces, con el fin de captar "el espíritu de la época y el espíritu del lugar"23, cada año alumnos y profesores realizaron sucesivas expediciones, desde la Pampa argentina hasta la Amazonia brasileña que perduran hasta el presente. Recorridos que siempre culminaron en el punto final con un acto poético y la creación de un objeto material que identificase esta presencia, desde una escultura hasta una edificación ligera y efímera que pudiese ser utilizada por la comunidad local2 ${ }^{24}$.

Además de esta experiencia docente, el resultado más significativo de la Escuela fue la creación del asentamiento denominado Ciudad Abierta. En 1970, un grupo de treinta profesores con sus familias, encabezados por Cruz y lommi, se asentaron en un terreno de $286 \mathrm{Ha}$, situado en Ritoque a 50 km de Valparaíso, formado por colinas y dunas frente al Pacífico, dividido en dos partes por una carretera - una alta en la colina, y otra baja frente al mar -; y a la vez separado de la playa por el cruce de una vía férrea. Allí surgió la Cooperativa Amereida, constituida por un conjunto de más de veinte edificaciones esparcidas entre las dunas y sobre la colina. El principio básico de la Cooperativa es que todo lo construido es propiedad colectiva, inclusive las viviendas individuales, y que las construcciones serían realizadas por profesores y alumnos con los escasos recursos disponibles y los materiales locales. El proceso de proyecto fue desenvuelto colectivamente en un proceso participativo de los arquitectos y artistas - llamado "en ronda" -, sin un plano o proyecto definido de antemano. En dos décadas - 1970 -1980 - se construyeron los espacios libres de uso público - denominadas ágoras porque en ellas se establecía el diálogo poético - y áreas cubiertas, provisorias y definitivas, utilizadas para las actividades docentes y

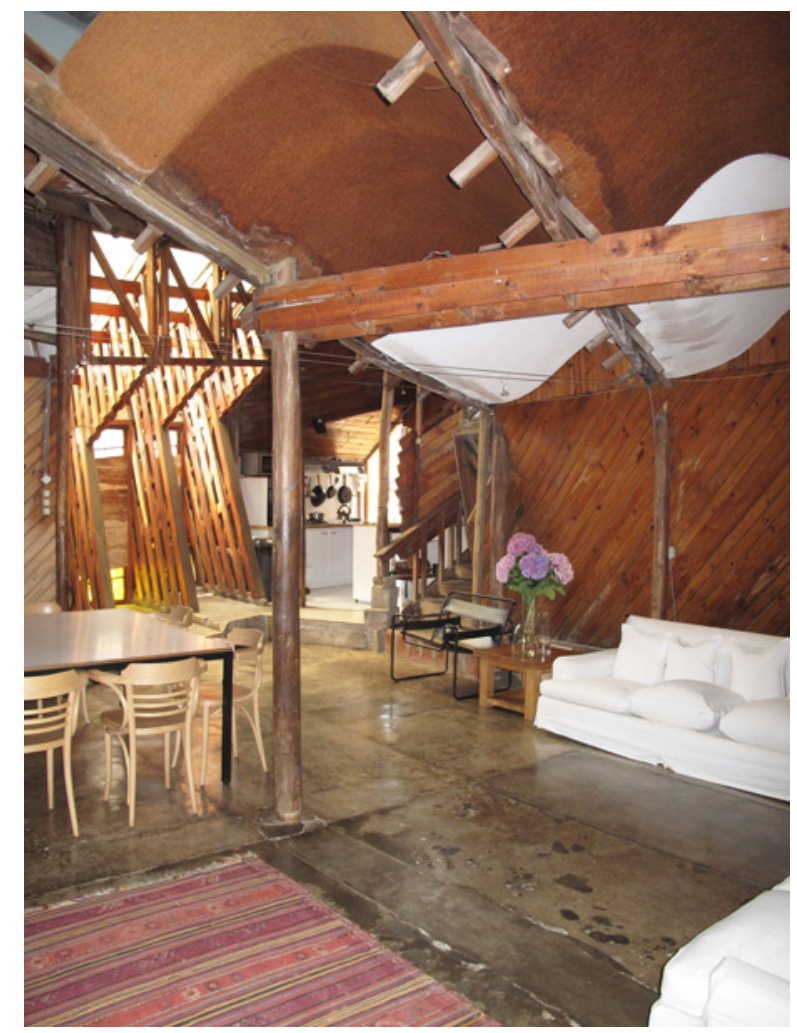

6 - Vista interior de una de las viviendas de la Hospedería del Banquete 


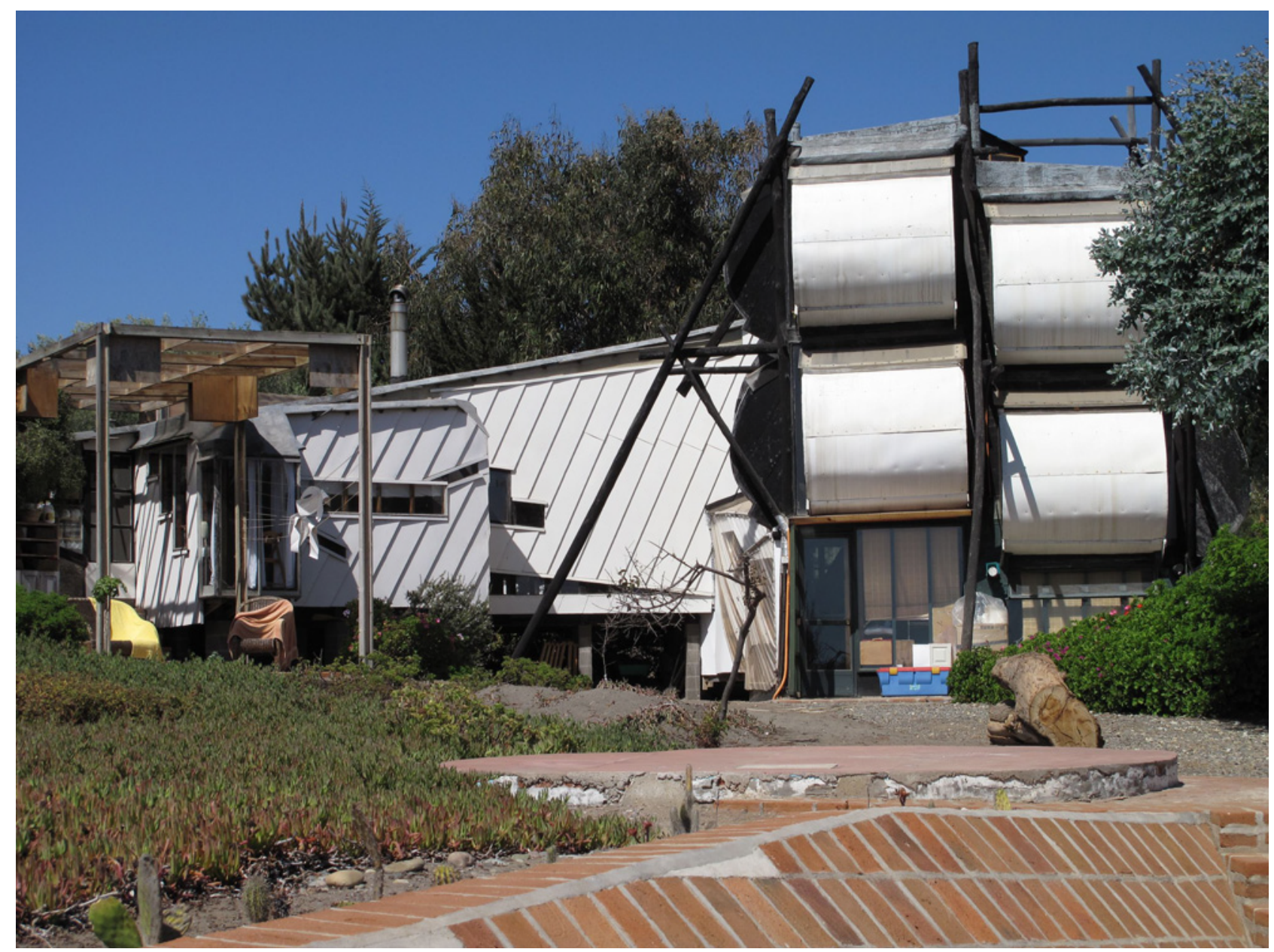

7- Hospedería La Alcoba

recreativas; el cementerio, un anfiteatro construido en 2001, un oratorio al aire libre, el edificio de la sala de música y el palacio del Alba y el Ocaso (1982), que originalmente albergaría 4 viviendas, pero que por mandato poético se decidió no sería concluido, convertido entonces como un centro de reuniones. Obras que fueron esparcidas sobre el territorio, en una persistente integración con la topografía, los árboles y las colinas. Si la Sala de Música (1972) - casi un cubo blanco de madera, con un núcleo central de iluminación - quedó situado en un área plana, el anfiteatro aprovechó la pendiente del terreno en la parte superior de la colina; mientras la densa vegetación creó el silencio indispensable en el ascético cementerio. Entre viviendas y edificios comunita- rios, surgieron las esculturas que acompañaron los actos poéticos, así como los espacios de congregación de los alumnos; sin un núcleo central, sin ejes viarios, ajenos a los tradicionales trazados regulares, y relacionados con las teorías urbanas y sociales de los situacionistas; tales como la imagen dinámica de la "deriva" y el juego y el nomadismo de la naked city de Guy Debord y Constant Nieuwenhuy ${ }^{25}$.

En la visión de Cruz, lommi y el equipo de profesores que se asentaron en Ciudad Abierta, asumía un carácter esencial la relación con la naturaleza; la veneración del panta rei, en su específica particularidad chilena. La localización en un sitio agreste implicaba asumir su carácter virginal e incidir circunstancialmente sobre el 
entorno. La experiencia de profesores y alumnos debía asumir y transformar en una acción poética la lectura e interpretación de sus elementos esenciales: el extenso océano Pacífico, la persistente movilidad de las dunas; el profundo azul del cielo con el brillo de la Cruz del Sur vista desde la colina. De allí, que los edificios y el sistema vial se posan sobre el paisaje, casi en forma imperceptible: las viviendas sobre pilotis flotan sobre las dunas, evidenciando su carácter efímero y circunstancial; que es la vida del ser humano frente a la eternidad de la naturaleza. Se trata de una actitud contrapuesta al materialismo de la sociedad actual, que permita imbuir a los estudiantes de la espiritualidad perdida. Como afirmó Próspero en La Tempestad de William Shakespeare (Escena I, Acto IV) "nosotros estamos hechos de la misma substancia de que están hechos los sueños y nuestra breve vida está envuelta en un sueño". En esa fragilidad de la existencia, se trata de potenciar en cada individuo el sentido poético de su capacidad creadora, e intentar que la generación de la forma arquitectónica, su "fundación", se origine en la poesía, porque como afirma Cruz "la palabra es inaugural, lleva, da luz"26. En este sentido, la comunidad utópica creada estuvo más próxima a las experiencias de los hippies norteamericanos de los años sesenta - la Drop City en Arizona, conformada por viviendas provisorias construidas con materiales locales, de desechos industriales o de la interpretación popular de los domos geodésicos de Buckminster Fuller -, que de la estética refinada de F.L. Wright en la sede de Taliesin ${ }^{27}$. Sin embargo, la persistente paradoja entre realidad y utopía, tuvo también sus facetas negativas. Fue señalado por Alfredo Jocelyn-Holt, prestigioso historiador chileno, el silencio mantenido durante la dictadura de Pinochet por los intelectuales y profesores residentes en Ciudad Abierta, actitud cuestionable por la presencia de un campo de concentración de presos políticos en Ritoque, no lejos de la comunidad.
El método de diseño desarrollado con los alumnos estuvo condicionado por la influencia del surrealismo y la adopción del pensamiento fenomenológico en la experiencia, tanto del contexto físico como del vínculo entre la vivienda y los usuarios $^{28}$. En relación con el diálogo entre arquitectura y naturaleza, su significación simbólica, así como en el uso de los materiales naturales, interpretando sus significados prácticos y míticos, resultó significativa la figura de Juan Borchers (19101975), cuyo principal libro de teoría estuvo dedicado a Alberto $\mathrm{Cruz}^{29}$. Y también la filosofía de Gastón Bachelard, al afirmar: "Así, frente a la hostilidad, frente a las formas animales de la tempestad y el huracán, los valores de protección y resistencia de la casa se transponen en valores humanos. La casa adquiere las energías físicas y morales de un cuerpo humano"30. La negación de los paradigmas establecidos por la sucesión de movimientos estéticos de la arquitectura - Racionalismo, International Style, Brutalismo, Postmodernismo, High Tech, Deconstructivismo, Minimalismo -, los vinculó a los movimientos artísticos de la segunda postguerra, basados, tanto en la fantasía onírica del creador, la posesión angustiosa de la materia primitiva y la inspiración asumida del mundo formal de la vida cotidiana. Las obras de Ciudad Abierta, están próximas al diálogo entre escultura y arquitectura de Jean Tinguely, Frederick Kiesler, André Bloc, Bruce Goff, el Grupo SITE y el austriaco Hundertwasser ${ }^{31}$; así como a los movimientos pictóricos y escultóricos del Informalismo, el Expresionismo Abastracto, el Arte Povera y el Land Art. Entre otros citemos la obra del chileno Roberto Matta y su hijo Gordon Matta Clark; Alberto Giacometti, Albrto Burri, Antoni Tapiés, Whilem de Koonig, Francis Bacon, Robert Rauschenberg, Joseph Beuys.

El aporte más interesante del conjunto radica en el diseño de las casi veinte 


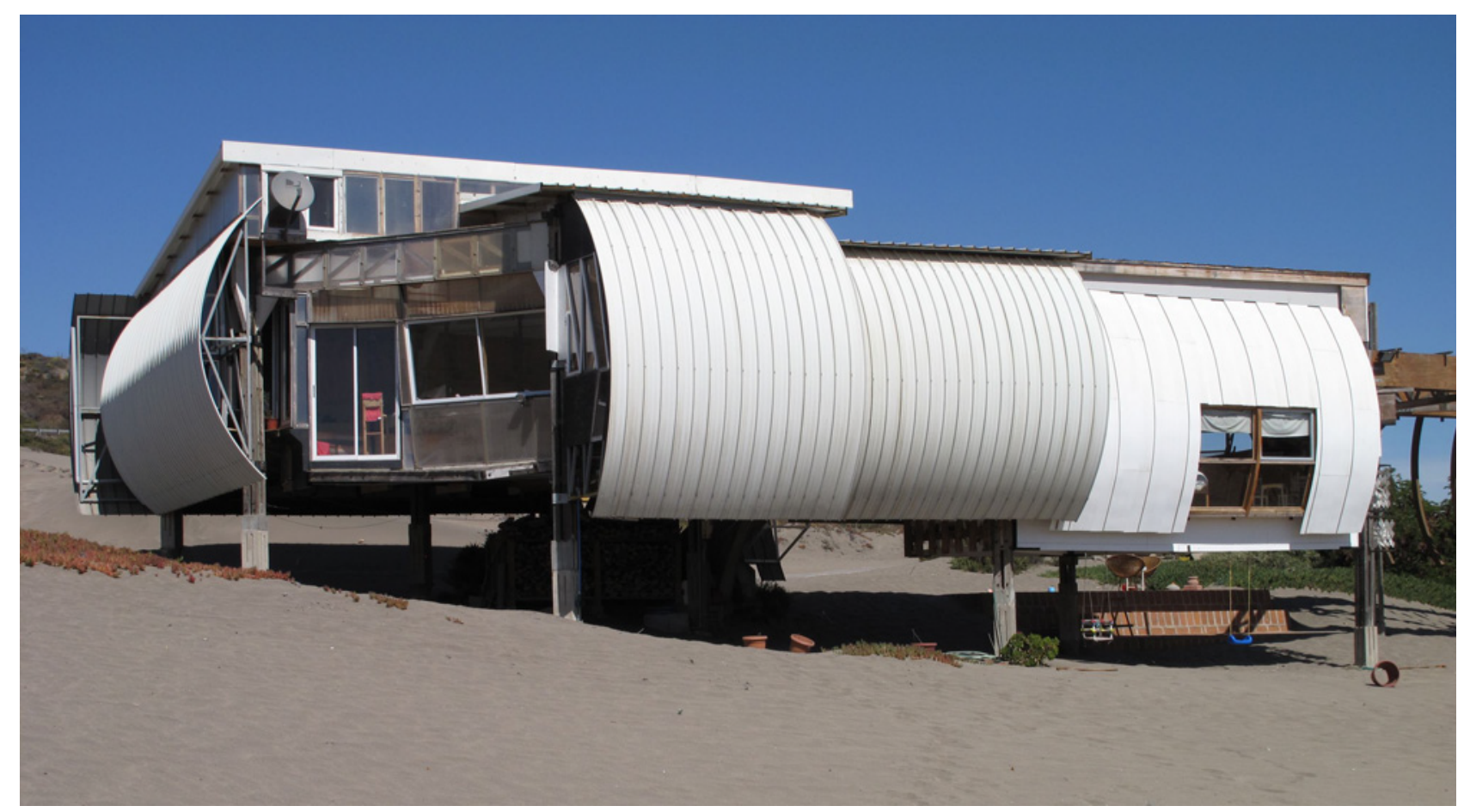

8 - Hospedería Colgante o Taller de Obras

viviendas esparcidas entre las dunas y el promontorio alto. Llamadas "hospederías", parten del principio que a la vez que albergan la vida familiar, son también espacio de convivencia, de trabajo, en los que pueden ser alojados los circunstanciales visitantes de Ciudad Abierta. De allí el carácter extrovertido de algunos ejemplos, la multiplicación de puertas de acceso, la continuidad espacial de los locales. Así los nombres poéticos de las Hospederías - el Banquete, de la Entrada, del Confín, de Los Diseños, de la Alcoba, del Errante, los Signos, Vestal del Jardín, Rosa de los Vientos, Taller de Obras - se identifican con el carácter de cada acto poético que le dio origen, así como por la adecuación a los condicionantes ecológicos - la movilidad de las dunas, las fuertes variaciones de temperatura entre el invierno y el verano, los intensos vientos del Pacífico. El debate sobre las diferentes experiencias espaciales y formales estuvo condicionado por el carácter de las funciones adecuadas a las formas de vida de cada usuario y por el uso de materiales locales - ladrillo, madera y lona -, así como también el empleo de estructuras metálicas, de hormigón, y revestimientos de chapas corrugadas, que fueron utilizadas en un diseño progresivo, casi espontáneo, sin prefiguraciones proyectuales: tal es el caso del la Hospedería Colgante o Taller de Obras (2004). La identificación de la hospedería de la Entrada (1984), elevada sobre pilotis, ocurre por un sistema de tubos sonoros que son accionados por el viento. La Alcoba, está caracterizada por los muros curvos de chapa metálica y de fibrocemento que protegen los locales del fuerte viento marino. La Hospedería del Banquete (1974) está formada por dos viviendas articuladas unidas por un alto techo protector del sol y la lluvia. Una de las obras más complejas es la Hospederia del Errante, primero diseñada por Miguel Eyquem (1981); luego reconstruída por Manuel Casanueva Carrasco en 1995. Fue concebida como un centro de reunión y de alojamiento de visitantes, y su forma exterior definida por paneles de cemento perforado sustentados 


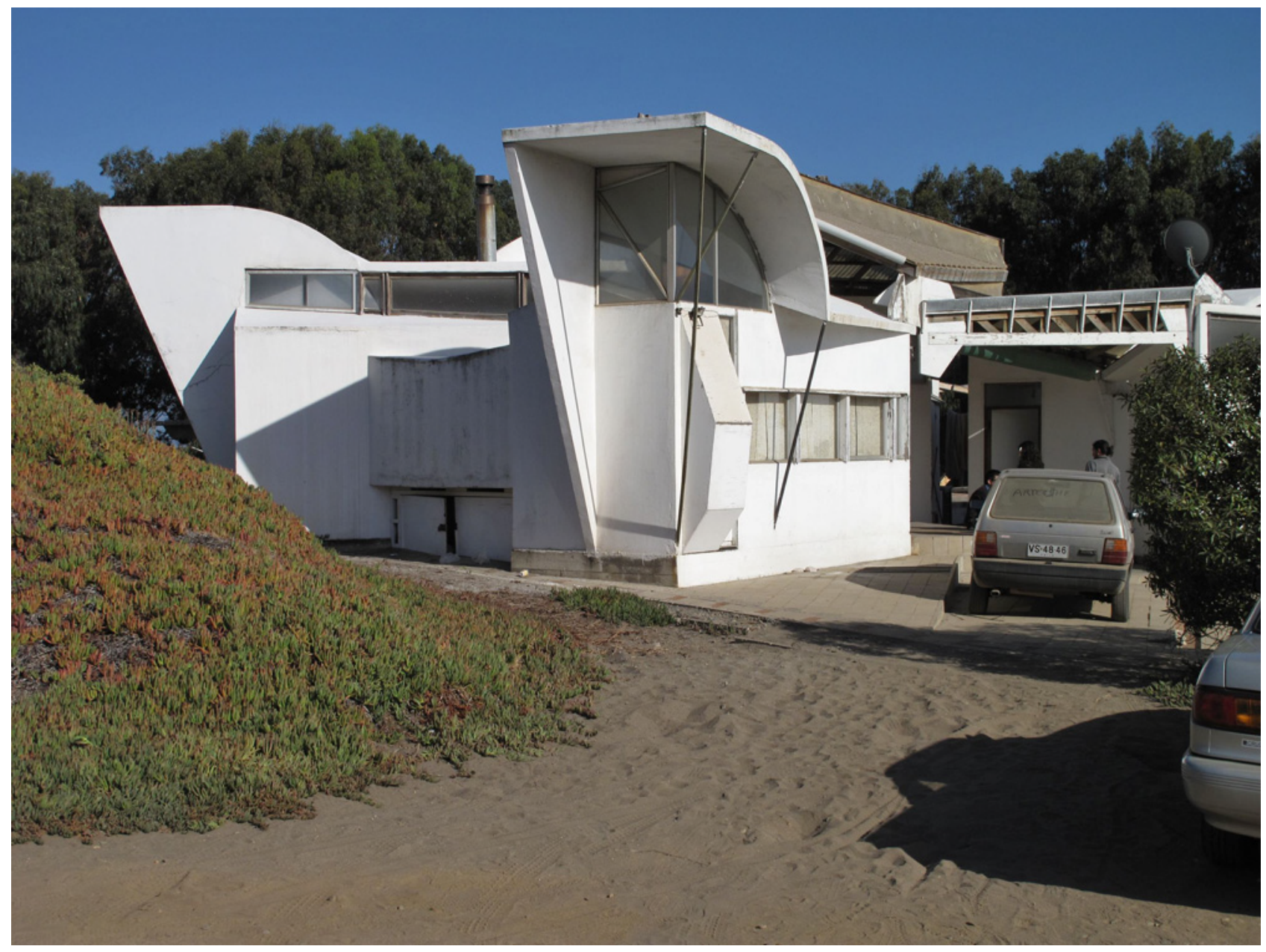

9 - Hospedería Rosa de los Vientos.

por una estructura metálica interior; que por una parte constituyen filtros que atenúan la luz solar, por otra, en su forma irregular se adaptan al flujo de viento, con el fin de ofrecerle la menor resistencia posible. En general, todas están caracterizadas por el tratamiento interior con madera natural, y las formas irregulares de los locales son consecuencia de la diversidad de elementos estructurales utilizados. Constituye un conjunto de viviendas sumamente original, caracterizado por la libertad compositiva del diseño, la libre combinación de materiales y formas, la relación de la obra con el espacio exterior, así como las configuraciones inéditas de protección de las inclemencias del clima. La negación de los esquemas cartesianos del Movimiento Moderno ${ }^{32}$ desembocaron en un "deconstructivismo" espontáneo que precedió a la difusión internacional del "estilo", así como en una libre interpretación del "regionalismo"; que sin duda establecieron un significativo antecedente en obras recientes de la arquitectura chilena. Son deudoras a Ciudad Abierta la casa Rivo en Valdivia de Pozo \& Von Ellrichshausen (2003); el prototipo m7 de la Cooperativa URO1 en Punta de Gallo, Tunquén (2001); la casa Wall en Santiago de Chile de FAR, Frohn \& Rojas; las Termas de Villarica de Germán del Sol (2003); las casetas y miradores turísticos del Grupo Talca en Villarica, entre otra ${ }^{33}$. Sin embargo, lo que diferencia Ciudad Abierta del resto de las experiencias chilenas y latinoamericanas, es la continuidad de una forma de vida 
ascética y espartana, poco común en la dinámica actual impuesta por el neoliberalismo globalizado. Ante las amenazadoras sombras del pesimismo que sobrevuelan el mundo en que vivimos, este rincón utópico sobre la Tierra demuestra que la redención humana todavía es posible.

\section{Roberto Segre}

Valparaíso - Río de Janeiro, marzo-abril 2011.

\section{Bibliografia:}

ALEXANDER, Christopher; HIRSHEN, Sanford; ISHIKAWA Sara; COFFIN Christie; ANGEL, Shlomo; Houses Generated by Pattems. Berkeley: Center for Environmental Structure, 1969.

BACHELARD, Gastón. La Poética del Espacio. México DF: Fondo de Cultura Económica, 1974.

BENÉVOLO, Leonardo. Historia de la Arquitectura Modema.ll tomos, Madrid: Taurus, 1963.

BERENSTEIN JACQUES, Paula (Org.). Apologia da Deriva. Escritos situacionistas sobre a cidade. Rio de Janeiro: Casa da Palavra, 2003.

BORCHERS, Juan. Institución Arquitectónica. Santiago de Chile: Editorial Andrés Bello, 1968.

BRIERLY, Comelia. Tales of Taliesin. Rohnert Park, CA.: Pomegranate Communications Inc., 2000.

BROWNE, Enrique. Otra arquitectura en América Latina. México DF.: G. Gili, 1988.

CAVERI, Claudio. El hombre a través de la arquitectura. Buenos Aires: Carlos Lohé, 1967.

CIORAN, Emil M. História e Utopia. Rio de Janeiro: Editora Rocco, 2010.

CRUZCOVARRUBIAS, Alberto Cruz. Elacto arquitectónico. Valparaíso: Ediciones Universitarias de Valparaíso. Pontificia Universidad Católica de Valparaíso, 2010.

ELIASH, Humberto; MORENO, Manuel. Arquitec- tura y Modernidad en Chile. Una Realidad Múltiple, 1925-1965. Santiago de Chile: Ediciones Universidad Católica de Chile, 1989.

FERNÁNDEZ, Roberto. La ilusión proyectual. Una historia de la arquitectura argentina, 1955-1995. Mar del Plata: Facultad de Arquitectura, Urbanismo y Diseño. Universidad Nacional de Mar del Plata, 1996.

FERNÁNDEZ-GALIANO, Luis (Edit.). Arquitectura: más por menos. Madrid: Fundación Arquitectura y Sociedad, 2010.

FERNÁNDEZ-GALIANO, Luis (Edit.), Atlas. Arquitecturas del siglo XXI. América. Fundación BBVA, Bilbao, 2010.

FIEDLER, Jeannine (Edit.). Bauhaus. Tandem Verlag $\mathrm{GmbH}$ : Könemann, 2006.

GARCÉS, Andrés (Edit.). Desvíos de la deriva: experiencias, travesías y morfologías". Madrid: Departamento de Actividades Editoriales del Museo Nacional Centro de Arte Reina Sofía, 2010.

GUINSBURG, J; LEIRNER, Sheila (Orgs.), O Surrealismo. San Pablo: Editora Perspectiva, 2008.

GONZÁLEZ LOBO, Carlos. Vivienda y Ciudad Posibles. Bogotá: Escala, 1999.

GUTIÉRREZ, Ramón. Arquitectura y Urbanismo en Iberoamérica. Madrid: Ediciones Cátedra, 1983.

LEPIK, Andrés (Edit). Small Scale Big Changes. New Architectures of Social Engagements. Nueva York: The Museum of Modern Art, 2010.

LEZAMA LIMA. Confluencias. Selección de Ensayos. Selección y prólogo, Abel E. Prieto. La Habana: Editorial Letras Cubanas, 1988.

LÖWY, Michael. A Estrela da Manhã. Surrealismo e Marxismo. Rio de Janeiro: Civilização Brasileira, 2002.

O'GORMAN, Edmundo. La invención de América, el universalismo de la cultura de Occidente. México DF: Fondo de Cultura Económica, 1958.

OPPENHEIMER DEAN, Andrea \& HURSLEY, Timothy. Rural Studio. Samuel Mockbee and an Architecture of Decency. Nueva York: Princeton Architectural Press, 2002.

PENDLETON-JULIAN, Ann M. The Road That is Not a Road, and the Open City, Ritoque, Chile. Cambridge, Mass.: The MIT Press, 1996. 
PÉREZ DEARCE, Rodrigo; PÉREZ OYARZÚN, Femando. Escuela de Valparaíso. Grupo Ciudad Abierta. Sevilla: Tanais Ediciones, 2003.

ROJAS MIX, Miguel. Los cien nombres de América. Eso que descubrió Colón. Barcelona: Editorial Lumen, 1991.

ROJAS MIX, Miguel. América Imaginaria. Barcelona: Editorial Lumen, 1992.

SEGRE, Roberto. Las estructuras ambientales de América Latina. México DF: Siglo Veintiuno Editores, 1977.

TORRENT SCHNEIDER . Arquitectura reciente en Chile. Las lógicas del proyecto. Santiago de Chile: Ediciones ARQ., Facultad de Arquitectura, Diseño y Estudios Urbanos. Pontificia Universidad Católica de Chile, 2000.

WRIGHT, Frank Lloyd. Testamento. Turín: Luigi Einaudi, 1963.

\begin{abstract}
${ }^{1}$ Agradezco la colaboración del Profesor de la Escuela de Arquitectura y Diseño de la PUCV Fernando M. Espósito Galarce, quien me facilitó la documentación sobre la Ciudad Abierta.
\end{abstract}

${ }^{2}$ Ver: E.M. Cioran, História e Utopia. Rio de Janeiro: Editora Rocco, 2010.

${ }^{3}$ Mike Davis, "Planet of Slums. Urban Involution and the Informal Proletariat", en: New Left Review No. 26, marzo/abril 2004, Londres, pp. 5-34.

4 Michael Löwy, A Estrela da Manhã. Surrealismo e Marxismo. Rio de Janeiro: Civilização Brasileira, 2002., pag. 9.

5 "Epicureismo" en, Dizionario Letterario Bompiani delle Opere e dei Personaggi di Tutti i Tempi e Tutte le Letterature. Milán: Valentino Bompiani Editore, 1947, Tomo I, A-B, pág. 67.

${ }^{6}$ William Morris formaba parte del grupo The Brotherhood, conjuntamente con Ruskin y Tennyson, dedicado a estudiar la cultura medieval. En 1862 forma la sociedad Morris, Marshall, Faulkner \& Co., para la producción de objetos artesanales que no tuvo éxito y cerró en 1875. Ver: Leonardo Benévolo, Historia de la Arquitectura Moderna. Madrid: Taurus, 1963, Tomo I, pág. 229.

7 Resulta emocionante verificar el sentido de comunidad que existía en la escuela del Bauhaus, el entusiasmo y alegría de profesores y estudiantes al participar en las actividades extra-curriculares - los conciertos, las representaciones teatrales, los bailes, las fiestas, las actividades deportivas y gimnásticas, los viajes a las playas en el verano -, documentadas en las fotos artísticas que lograron salvarse de la furia destructiva del nazismo. Ver: Jeannine Fiedler (Edit.), Bauhaus. Tandem Verlag GmbH: Könemann, 2006.

8 Cornelia Brierly, Tales of Taliesin. Rohnert Park, CA.: Pomegranate Communications Inc., 2000, pág. 29.

9 Frank Lloyd Wright, Testamento. Turín: Luigi Einaudi, 1963, pág. 121.

${ }^{10}$ El Rural Studio de Samuel Mockbee fue muy importante em los Estados Unidos porque desarrolló un camino creador e innovador, con soluciones arquitectónicas inéditas y la utilización de materiales poco comunes, en algunos casos de desechos de papel y vidrio, con el fin de resolver el espacio de vida de las comunidades negras pobres de los estados del sur. Su obra recién fue reconocida después de su fallecimiento en 2001. Ver: Andrea Oppenheimer Dean \& Timothy Hursley, Rural Studio. Samuel Mockbee and an Architecture of Decency. Nueva York: Princeton Architectural Press, 2002.

11 Andrés Lepik (Edit.), Small Scale Big Changes. New architectures of Social Engagements. Nueva York: The Museum of Modern Art, 2010.

12 Luis Fernández-Galiano (Edit.), Arquitectura: más por menos. Madrid: Fundación Arquitectura y Sociedad, 2010.

13 Ramón Gutiérrez, Arquitectura y Urbanismo en Iberoamérica. Madrid: Ediciones Cátedra, 1983, pág. 213.

14 Carlos González Lobo imaginó soluciones urbanas que pudiesen ser construidas con los proyectos de viviendas populares de barro, ladrillo y madera. Carlos González Lobo, Vivienda y Ciudad Posibles. Bogotá: Escala, 1999, pág. 207.

15 Roberto Segre, Las estructuras ambientales de América Latina. México DF: Siglo Veintiuno Editores, 1977, pág.227.

16 Las obras construidas en la Comunidad Tierra, tienen cierta relación con las de Ciudad Abierta, en su libertad de diseño, ajenas a los paradigmas utilizados para identificar a la arquitectura "de la pobreza". Ver: Roberto Fernández, La ilusión proyectual. Una historia de la arquitectura argentina, 1955-1995. Mar del Plata: Facultad de Arquitectura, Urbanismo y Diseño. Universidad Nacional de Mar del Plata, 1996, pág. 102; y también: Claudio Caveri, El hombre a través de la arquitectura. Buenos Aires: Carlos Lohé, 1967.

17 Christopher Alexander, Sanford Hirshen, Sara Ishikawa, Christie Coffin, Shlomo Angel, Houses Generated by Patterns. Berkeley: Center for Environmental Structure, 1969.

18 Edmundo O'Gorman, La invención de América, el universalismo de la cultura de Occidente. México DF: Fondo de Cultura Económica, 1958. 
19 José Lezama Lima, Confluencias. Selección de Ensayos. Selección y prólogo, Abel E. Prieto. La Habana: Editorial Letras Cubanas, 1988, pág.286.

${ }^{20}$ Como demostró detalladamente Rojas Mix, la identificación de América tuvo varias denominaciones. El escritor argentino Ricardo Rojas la definió como Eurindia; y J.W. Powell, utilizó la palabra Amerindia. También se utilizan los términos Iberoamérica e Hispanoamérica. Cruz y .lommi prefirieron valorizar el vínculo de América con la herencia cultural europea que se remonta a Roma, y que es la raíz esencial de nuestra cultura, sin menospreciar la importancia de las culturas indígenas en los países del eje andino. Ver: Miguel Rojas Mix, Los cien nombres de América. Eso que descubrió Colón. Barcelona: Editorial Lumen, 1991, pág. 401; y América Imaginaria. Barcelona: Editorial Lumen, 1992.

${ }^{21}$ Ann M. Pendleton-Jullian, The Road That is Not a Road, and the Open City, Ritoque, Chile. Cambridge, Mass.: The MIT Press, 1996, pág. 49

${ }^{22}$ Fernando Pérez Oyarzún, "Escuela de Valparaíso", en The Harvard Architecture Review Volumen 9, Cambridge, Mass., 1993, pp. 82-101.

${ }^{23}$ Enrique Browne, Otra arquitectura en América Latina. México DF.: G. Gili, 1988, pág. 9.

24 Fernando Pérez Oyarzún, "La vida de la arquitectura: la Escuela de Valparaíso y el Taller de Juan Borchers", en Andrés Garcés y Departamento de Actividades Editoriales del Museo Nacional Centro Reina Sofía (Edits.), Desvíos de la deriva: experiencias, travesías y morfologías" Madrid: Centro de Arte Reina Sofía, 2010, pág. 146.
25 Paula Berenstein Jacques (Org.), Apologia da Deriva. Escritos situacionistas sobre a cidade. Rio de Janeiro: Casa da Palavra, 2003, pág.21.

26 Alberto Cruz Covarrubias, El acto arquitectónico. Valparaíso: Ediciones Universitarias de Valparaíso. Pontificia Universidad Católica de Valparaíso, 2010, s/p.

${ }^{27}$ Rodrigo Pérez de Arce, "Tan lejos y tan cerca: la Ciudad Abierta y las Travesías", en Rodrigo Pérez de Arce y Fernando Pérez Oyarzún, Escuela de Valparaíso. Grupo Ciudad Abierta. Sevilla: Tanais Ediciones, 2003, pp. 13/17.

${ }^{28}$ Horacio Torrent Schneider, Arquitectura reciente en Chile. Las lógicas del proyecto. Santiago de Chile: Ediciones ARQ., Facultad de Arquitectura, Diseño y Estudios Urbanos. Pontificia Universidad Católica de Chile, 2000, pág. 13.

29 Juan Borchers, Institución Arquitectónica. Santiago de Chile: Editorial Andrés Bello, 1968.

30 Gastón Bachelard, La Poética del Espacio. México DF: Fondo de Cultura Económica, 1974, pág. 78.

31 Roberto Segre, "Surrealismo e Arquitetura", en J. Guinsburg; Sheila Leirner (Org.), O Surrealismo. San Pablo: Editora Perspectiva, 2008, pp. 543-565.

32 Humberto Eliash; Manuel Moreno, Arquitectura y Modernidad en Chile. Una Realidad Múltiple, 19251965. Santiago de Chile: Ediciones Universidad Católica de Chile, 1989, pág. 172.

Contato:

Professor Roberto Segre

PROURB - Programa de Pós-Graduação em Urbanismo Av. Reitor Pedro Calmon, 550. Prédio da FAU - Reitoria $5^{\circ}$ andar - sala 521 - Cidade Universitária

Rio de Janeiro, RJ - 21941-901

Tel: (+55 21) 2598-1990 / 2598-1984

Fax: (+55 21) 2598-1991

Artigo recebido em Maio de 2011

Artigo aprovado em Maio de 2011 